Actas del Seminario Internacional Destinos Turísticos Inteligentes:

nuevos horizontes en la investigación y gestión del turismo

Universidad de Alicante, 26 y 27 de octubre de 2017

\title{
El perfil del smart tourist en Ávila ${ }^{1}$
}

\author{
Libertad Troitiño Torralba \\ Universidad Complutense de Madrid, España \\ Departamento de Geografía Humana \\ Itroitin@ucm.es \\ María García Hernández \\ Universidad Complutense de Madrid, España \\ Departamento de Geografía Humana \\ mgarciah@ghis.ucm.es
}

\section{Resumen}

El presente trabajo pretende profundizar en el perfil del visitante actual en el contexto de los denominados Destinos Turísticos Inteligentes (DTI). Para ello, se realiza una reflexión inicial sobre la evolución del concepto, desde el denominado Turista 1.0 o Consumer, hasta el nuevo Smart Traveller, entendido este como el Viajero/ Turista 3.0 o Adprosumer. Los DTI han de conformarse atendiendo a criterios de sostenibilidad, accesibilidad, conocimiento e innovación tecnológica. Sin embargo, su consideración como smart, no ha de depender exclusivamente de su adecuación tecnológica, sino que tienen que trabajar por el fomento de un desarrollo eficiente que abogue, en primer lugar, por mejorar e incrementar la calidad de vida de los residentes y, en segundo término, por incorporar nuevas fórmulas de planificación y unidades de gestión turística, que contribuyan en la toma de decisiones y definición de políticas acordes a las necesidades y singularidades del territorio, considerando en todo momento al visitante, como referente o punto de partida del proceso de conversión en DTI. En este sentido, esta comunicación se aborda dichas circunstancias en un destino turístico español de dominante patrimonial, como es Ávila.

Palabras clave: Destinos Turísticos Inteligentes, Patrimonio, Experiencia, Visitantes

1. La comunicación se inscribe en el marco del proyecto de investigación «Nuevos enfoques para la planificación y gestión del territorio turístico: conceptualización, análisis de experiencias y problemas. Definición de modelos operativos para destinos turísticos inteligentes (TTI)». Ref-CSO2014-59193-R. Programa Estatal de I+D+i, Ministerio de Economía y Competitividad. 
Actas del Seminario Internacional Destinos Turísticos Inteligentes:

nuevos horizontes en la investigación y gestión del turismo

Universidad de Alicante, 26 y 27 de octubre de 2017

\section{Abstract}

This report intends to deepen the profile of the current visitor in the context of the so-called Intelligent Tourist Destinations (DTI). For this, an initial reflection is about the evolution of the concept tourist, from the so-called Tourist 1.0 or Consumer, to the new Smart Traveler, understood as the Traveler / Tourist 3.0 or Adprosumer. DTIs must comply with criteria of sustainability, accessibility, knowledge and technological innovation. However, destinations been considered as smart should not depend exclusively on their technological adequacy, but they must work for the promotion of efficient development that advocates. Firstly, to improve and increase the quality of life of residents, and secondly, to incorporate new planning recipes and tourism management units, which contribute to the decision making and definition of policies according to the needs and singularities of the territory, considering at all times the visitor, as a reference or starting point of the conversion process in DTI. Accordingly, this communication addresses this circumstance in a Spanish tourist destination, of dominant patrimonial, as is Avila.

Keywords: Smart Tourism Destination, Heritage, Experiences, Tourist/Travellers

\section{Introducción}

En el complejo entramado sistémico sobre el que se vertebra y conforma un destino turístico, hay una pieza que es clave y ha de considerarse cómo fundamental en los procesos de planificación y gestión, se trata de la demanda (Vera et al., 2011). Al abordar la realidad de los Destinos Turísticos Inteligentes observamos que, efectivamente, el discurso se orienta hacia la atracción de un mayor volumen de visitantes, sin embargo, las acciones y estrategias prioritarias se orientan hacia la oferta, es decir, qué servicios e infraestructuras debe ofrecer ese territorio al visitante, cómo ha de prepararse para captar su atención, qué nuevos productos deben incluirse para ser destinos de referencia, etc., Por el contrario, son limitados los proyectos de destino que incluyen estudios de público con los que ahondar en el conocimiento de las características, pautas de consumo, motivaciones y comportamientos de los visitantes una vez en destino.

Es innegable que las necesidades y características de los consumidores turísticos están cambiando, dada la generalización de las TIC's y el uso de los Smartphone. Por tanto, se hace primordial para los destinos (inteligentes o no), contar con análisis de demanda que partan de la obtención de información detallada referida a la afluencia y perfil de los visitantes, generándose 
Actas del Seminario Internacional Destinos Turísticos Inteligentes: nuevos horizontes en la investigación y gestión del turismo

Universidad de Alicante, 26 y 27 de octubre de 2017

nuevas bases de datos con las que enriquecer el denominado Big Data aplicado al turismo que poco a poco van generando los destinos. Sin duda, desde la planificación, gestión y política turística, disponer de información, no solo es una oportunidad, sino que ha de entenderse como una fortaleza de cara a la mejora del sistema turístico sobre el que se vertebra un territorio. Es evidente, que en la era informacional en la que vivimos (Castell, 2004), disponer de datos y documentación es tener poder, sin embargo, el punto clave es cómo procesar esa información y cómo canalizarla, de tal manera que los agentes implicados en la actividad turística sepan rentabilizarla, maximizando beneficios y minimizando impactos y efectos negativos en el destino.

Entre los retos de los destinos turísticos se encuentra alcanzar la excelencia, lo que requiere de una estrategia integral e integrada que incorpore dimensiones heterogéneas, sociales, funcionales, económicas, medioambientales, urbanísticas, culturales, turísticas, etc....A estas, los denominados Destinos Turísticos Inteligentes (DTI), añaden las vinculadas a la innovación e implementación de medios tecnológicos y soportes digitales. En esta línea, en España, el Plan Nacional e Integral de Turismo 2012-2015 en el bloque de medidas referidas a Destinos Inteligentes, incide en esta idea, «la necesidad de ofrecer servicios para el turista que sean diferenciales y altamente competitivos» lo que "obliga al sistema turístico nacional a buscar nuevos mecanismos para impulsar la innovación. En este ámbito, tanto el conocimiento como las nuevas tecnologías y, en especial, las de la información y las comunicaciones (TIC) son la base para los cambios que aporten valor en el mercado». (Ministerio de Energía, Turismo y Agenda Digital, PNIT 20122015, pp. 71)

En las primeras décadas del s. XXI, apostar por lo Smart es tendencia social y, en una actividad tan dinámica como es la turística, ha supuesto que esta línea de acción haya pasado de ser, a priori, una moda, a convertirse en uno de los objetivos prioritarios de los destinos, pues ser Smart Destination supone llegar a ser "un espacio turístico innovador, accesible a todos, consolidado sobre una infraestructura tecnológica de vanguardia que garantiza el desarrollo sostenible del territorio, facilita la interacción e integración del visitante con el entorno, e incrementa la calidad de la experiencia en destino y la calidad de vida de los residentes» (López; García, 2013).

Para alcanzar este codiciado objetivo España viene trabajando en el diseño de un marco homogéneo que ayude a la innovación en los destinos; de hecho, fue el primer país que definió unas directrices para el desarrollo 
Actas del Seminario Internacional Destinos Turísticos Inteligentes: nuevos horizontes en la investigación y gestión del turismo

Universidad de Alicante, 26 y 27 de octubre de 2017

de los DTI (SEGITTUR, 2013). En 2013, bajo el respaldo de la Asociación Española de Normalización y Certificación (AENOR), se conformó el Comité Técnico de Normalización AEN/CTN178² "Ciudades Inteligentes», del que el subcomité (SC)5 «Destinos turísticos» (UNE 178501 Sistema de gestión de los destinos turísticos inteligentes). La reglamentación define las especificaciones técnicas, que han de ser utilizadas por las empresas y los destinos, de manera voluntaria, para probar la calidad y la seguridad de la actividad, servicios y productos.

Cinco son los pilares sobre los que han de vertebrarse los DTI: Innovación, Tecnología, Accesibilidad, Sostenibilidad y Gobernanza. A los que habría que suponer, los de Infraestructuras (SC1), Gobierno y Movilidad (SC2), Energía y Medio ambiente (SC4), con el fin así de lograr ese proyecto futuro de territorios o ciudades sostenibles, preparados para el día a día de sus residentes. Un concepto integrado e integral que tendrá sin duda efectos más que positivos en la conversión de los destinos en Smart.

La literatura referida a los DTI, tiene su origen en los denominados territorios y ciudades inteligentes (Eger, 1997), entendidos tal y como señala Alfonso Vegara (2009), como aquellos que están enfocando con coherencia los retos de la globalización y los riesgos que esta genera. Se trata de ciudades innovadoras capaces de encontrar un equilibrio entre los aspectos de competitividad económica, cohesión y desarrollo social y sostenibilidad ambiental y cultural. A esta premisa, habría que añadirle una serie de aspectos que son fundamentales para entender la idiosincrasia de los DTI:

Tabla 1: Elementos diferenciales de los DTI

- Vienen impulsados por el sector turístico, tanto público como privado.

- El público objetivo es el visitante, no el ciudadano; aunque consecuencia inmediata será que el residente también se vea beneficiado.

- Los límites geográficos pueden coincidir o no con las delimitaciones municipales

- La interacción va más allá de la propia estancia en la ciudad. En los DTI comienza antes de que el visitante llegue al destino, continua durante su estancia y se prolonga hasta después de su marcha.

- Los DTI están ligados al incremento de competitividad del mismo y a la mejora de la experiencia del turista.

Fuente: López de Ávila, A. y García Sánchez, S. (2013)

2. El comité está presidido por la Sociedad de la Información (SETSI), la Federación Española de Municipios y Provincias y la Red Española de Ciudades Inteligentes (RECI). 
Actas del Seminario Internacional Destinos Turísticos Inteligentes: nuevos horizontes en la investigación y gestión del turismo

Universidad de Alicante, 26 y 27 de octubre de 2017

Sin duda el territorio es el eje central de la actividad turística, pues es donde confluyen todos los elementos sobre los que se estructura el sistema turístico (Vera et al., 2011), posee los recursos turísticos que suscitan inquietud y motivación sobre el potencial visitante para generar el desplazamiento (flujos turísticos) y es el soporte físico sobre el que se desarrollan la oferta, servicios e infraestructuras. Está asumido que los destinos están en un continuo proceso de adecuación y adaptación a las necesidades de la demanda, dado que el visitante es el objeto de atención, sin embargo, ¿cómo ha evolucionado el visitante?, ¿ंes posible hablar de un Smart tourist?, ¿cómo han incidido las TIC en las prácticas del visitante en destino?

Profundizar de algún modo en la obtención de información que contribuya a resolver estos interrogantes, es en parte, objetivo del presente trabajo. Sin embargo, el grueso de la investigación que se expone en el presente texto, se centra en la caracterización del Smart Tourist en un destino patrimonial como es Ávila, que está trabajando por posicionarse como uno de los Smart Heritage Destination de referencia en España. Conocer aspectos motivacionales, actividades en destino, fórmulas de viaje, así como cuestiones derivadas del uso de las ya no tan nuevas tecnologías, permitirá a los planificadores, gestores y políticos con competencia en materia turística perfilar estrategias de actuación acordes con los requerimientos explícitos de sus clientes y sujetas a las posibilidades singulares que brinda ese territorio, evitando la repetición de modelos que derivan en una banalización del lugar.

Se abre por tanto un interesante campo de investigación que permite obtener nuevos datos que enriquezcan el Big Data, con los que profundizar en la evolución de los territorios en la lógica de los DTI. En este sentido, esta comunicación se estructura en dos partes, la primera de ella centrada en una reflexión teórica sobre la evolución de la figura del turista, desde el denominado 1.0 hasta el actual 3.0, y una segunda, más aplicada, en la que se exponen los resultados de la encuesta implementada en la ciudad de Ávila, uno de los destinos piloto del proyecto de investigación «Nuevos enfoques para la planificación y gestión del territorio turístico: conceptualización, análisis de experiencias y problemas. Definición de modelos operativos para destinos turísticos inteligentes (TTI)» dentro del Programa Estatal de I+D+i, Ministerio de Economía y Competitividad. 
Actas del Seminario Internacional Destinos Turísticos Inteligentes:

nuevos horizontes en la investigación y gestión del turismo

Universidad de Alicante, 26 y 27 de octubre de 2017

\section{Del turista 1.0 Al turista 3.0}

Aunque en los últimos años se está prestando más atención al denominado Smart tourist/travellers (Mascaró, 2013), hay que seguir ahondando en el conocimiento de los perfiles del visitante, diferenciando a su vez el tipo de destino al que viajan. El Manual de Destinos Inteligentes (DTI) (INVAT-TUR, 2015) considera el análisis de la demanda como uno de los factores que justifican la configuración de los DTI. Los visitantes de hoy en día cuentan con más información, el acceso a esta es inmediato y compartir los lugares visitados, actividades realizadas y percepciones obtenidas a través de las redes sociales, es parte ya de la propia experiencia del viaje.

El libro blanco de los Destinos Turísticos Inteligentes (Blanco, 2015) realiza una sencilla radiografía de los turistas actuales:

- El uso de Internet y de dispositivos móviles está cada vez más presente a lo largo de todo el ciclo de viaje, demandando conectividad en sus desplazamientos y estancias

- Sus patrones motivacionales son más amplios y flexibles

- La búsqueda de experiencias vitales y auténticas se convierte en un referente cada vez más extendido entre los turistas globales

- Son especialmente sensibles a los precios, a la seguridad y al entorno donde se produce su viaje

- Tienen una mayor apertura a considerar otras opciones y tipos de viaje basados en ofertas que nacen de los modelos colaborativos en sus diferentes modalidades

Sin duda, la generalización del uso de Internet y los medios digitales ha supuesto importantes variaciones en el sector turístico y, también, en el usuario. El manejo de la tecnología y la habilidad de manejo de smartphone, tablets, smartwacth, apps, redes sociales, permite hacer una primera diferenciación de la demanda que, aunque usada, a priori, en el ámbito del sector educativo, se ha hecho extensiva a otros ámbitos, y que también podemos aplicar a la realidad turística. Estamos hablando de los nativos digitales y los inmigrantes digitales (Prensky, 2001), entendiéndose los primeros como las personas nacidas a partir de la década de los 90 del siglo XX, que han estado rodeadas desde temprana edad por las nuevas tecnologías (internet, dispositivos móviles, consolas de videojuegos, etc.) y los nuevos medios de comunicación que consumen masivamente, lo que ha derivado 
Actas del Seminario Internacional Destinos Turísticos Inteligentes:

nuevos horizontes en la investigación y gestión del turismo

Universidad de Alicante, 26 y 27 de octubre de 2017

en maneras de pensar, comprender e interpretar el mundo diferenciadas; mientras que los segundos, se refiere a aquellas personas nacidas y educadas antes del auge de las nuevas tecnologías.

Respecto a esta clasificación hay voces críticas que plantean que no se trata tanto de una diferenciación por edades, sino de habilidades. Lo que sí es veraz, es que el "nuevo turista» consume de una forma diferente, demanda productos novedosos, organiza sus viajes de una manera distinta y sus motivaciones divergen de las que poseen los inmigrantes digitales.

El volumen de información visual condiciona sus criterios de selección de destinos y actividades a realizar, al igual que demandan que la información sea facilitada de forma efímera y breve. Hosteltur señalaba en el monográfico «Turismo 2.0. Una sección paradigmática del in-formar» (2009. p.7) que los nativos digitales «aprenden en la red y de la red. Si tenemos en cuenta la cantidad de información que circula en la red, el acceso inmediato que tienen a ella y la capacidad de gestionarla de forma natural, se comprenderá la potencialidad de internet como instrumento de aprendizaje. La capacidad de influir y de ser influido se multiplica en este perfil de visitante de forma exponencial y puede afectar a su decisión de compra».

En el proceso evolutivo del perfil del visitante inciden de manera inevitable los cambios económicos y sociales que dinamizan el turismo, la ampliación del tiempo dedicado al ocio, la mejora en los medios de transporte y vías de comunicación, lo que ha contribuido a la conquista de nuevos territorios (física y digitalmente) y ha permitido acortar distancias, al mismo tiempo que se han mejorado las rentas y la capacidad de gasto turístico por parte de los individuos; además, uno de los aspectos fundamentales en los múltiples perfiles de la demanda, es la concepción de la vacación y el viaje turístico como necesidad básica, lo que ha derivado en motivaciones heterogéneas que, a su vez, se han materializado en modalidades y prácticas turísticas en destino (turismo de compras, de salud, deportivo, experiencial, colaborativo...)

En este sentido, el concepto de visitante se ha ido especializando, desde los viajeros románticos del s. XIX, que como señala Díaz Larios (1996) reflejaban «la curiosidad por la otredad, en una época en que lo exótico, lo fantástico y lo insólito contribuían de manera decisiva a un nuevo imaginario colectivo, produce un extraordinario aumento de notas, diarios, epistolarios, guías y memorias de viajes", hasta el smart traveller del s. XXI. Se recupera por tanto la idea de «viajero», frente a la de turista, en ocasiones con 
Actas del Seminario Internacional Destinos Turísticos Inteligentes:

nuevos horizontes en la investigación y gestión del turismo

Universidad de Alicante, 26 y 27 de octubre de 2017

connotaciones peyorativas, dada su vinculación a prácticas masivas. Para el viajero actual, lo experiencial cobra un significado relevante, además el estar conectado a la red influye en la calidad de la vivencia y, mientras que los clásicos, plasmaban sus recorridos y descubrimientos en láminas y textos literarios, el smart traveller lo hace a través de fotografías y cuadernos de viaje que comparten en las redes sociales.

La diferenciación positiva entre viajero y turista es fácilmente identificable en el discurso de la promoción y comercialización turística en los medios digitales (prensa, blogs de turismo, redes sociales...), con manifestaciones como "¿ies peligroso parecer un turista?» (Sader,2016); "eres un viajero apasionado que quiere vivir experiencias únicas y evitas a toda costa comportarte como un turista. Quieres sentirte único y, sobre todo, estar tan integrado como un local»; "huyes de los viajes en grupo, en que todos los viajeros vais a hacer las mismas actividades dirigidas, marcadas y nada personalizadas»; eliges como destino países que son tendencia para conocerlos de una forma más intensa y desconocida hasta el momento» o "vives conectado a los dispositivos tecnológicos ya que parte de tus experiencias viajando quieres compartirlas de forma masiva. Valoras las opiniones y recomendaciones que encuentras en redes y basas parte de tus decisiones en la información que te ofrece el mundo on line» (Turismo y viajes, 2016)

Si tomamos de referencia las definiciones realizadas por la Organización Mundial del Turismo, ¿qué se entiende por viajero? «toda persona que se desplaza entre dos o más países diferentes o entre dos o más lugares dentro de su país de residencia habitual; $y$, ¿̇por visitante?, «toda persona que viaje, por un período no superior a 12 meses, a un país/lugar diferente de aquel donde tiene su residencia habitual y que el motivo principal de la visita no sea ejercer una actividad que se remunere en el territorio visitado"; ¿qué implica ser turista?, "estar al menos una noche en un medio de alojamiento colectivo o privado en el país o lugar visitado».

De esta manera, la connotación negativa asociada al rol de «turista» ha sido otorgada por la sociedad, las malas praxis individuales, empresariales y de las administraciones públicas (ausencia de planificación, mala gestión, inexistencia/debilidad de políticas...), han derivado en una cierta «demonización» del vocablo turista (turismofobia) (Reverté; Clavé, 2008), cuando en sensu stricto, todo turista es viajero, y todo viajero, que pernocta en su lugar diferente al de residencia habitual, es turista. La idea bucólica del viaje y por ende del viajero, responde a esa búsqueda de lo experiencial, de lo único, 
Actas del Seminario Internacional Destinos Turísticos Inteligentes: nuevos horizontes en la investigación y gestión del turismo

Universidad de Alicante, 26 y 27 de octubre de 2017

de lo diferente y singular, frente al consumo masivo ${ }^{3}$. Por tanto, es la disociación entre lo sensorial y motivacional frente a la lógica consumista asociada al mercado turístico. Si bien, estas formas de hacer turismo, también han entrado en los canales de producción y comercialización como otras prácticas ya consolidadas.

En esta lógica, desde un enfoque de marketing y mercado se analiza al visitante como consumidor turístico, y se pone de manifiesto la necesidad de prestar atención a todas las fases del ciclo de consumo, desde que se plantea la necesidad del viaje hasta que, una vez concluidas sus vacaciones, vuelve a su lugar de residencia habitual y gestiona sus recuerdos de ese viaje. La propia evolución de la actividad y el sector turístico, así como la aparición e

Figura 1: características de los perfiles de turistas. Del 1.0 al 3.0

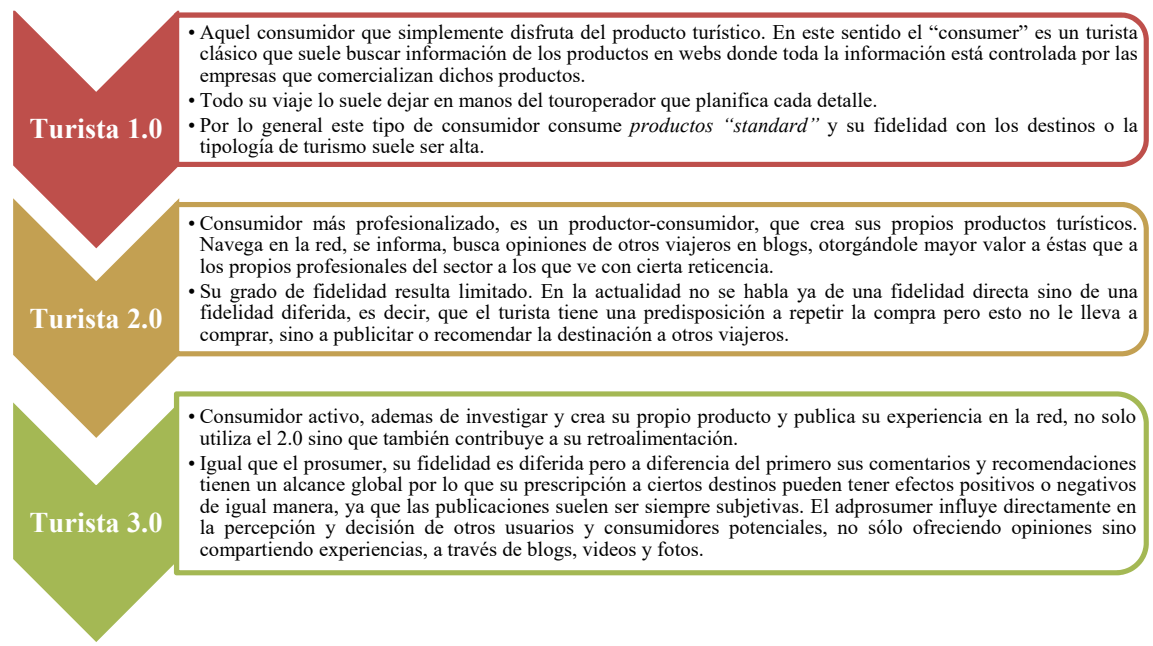

Elaboración propia a partir de González, L. (2017) Cinco características que diferencian al turista 3.0. [Recuperado de http://www.cognodata.com/notas_de_prensa/cincocaracteristicas-que-diferencian-al-turista-3-0/]; Caro, J. L., Luque, A. M., \& Zayas Fernández, B. (2014). Aplicaciones tecnológicas para la promoción de los recursos turísticos culturales.

3. Nadal, P. (2011) ¿Por qué ser turista es malo y ser viajero, mola? [Recuperado de http:// elpais.com/elpais/2010/11/14/paco_nadal/1289689200_128968.html] 
Actas del Seminario Internacional Destinos Turísticos Inteligentes:

nuevos horizontes en la investigación y gestión del turismo

Universidad de Alicante, 26 y 27 de octubre de 2017

inclusión de las tecnologías de la información, ha permitido establecer una nueva clasificación de visitante, que responde no solo a pautas de consumo, sino también a la temporalidad social en la que se enmarca cada grupo. De esta manera, se habla del turista 1.0 o Consumer, turista 2.0 o Prosumer y el turista 3.0 o Adprosumer (Redondo, 2016).

Otra clasificación más sencilla a la hora de diferenciar a los visitantes es la que establece TripAdvisor, "la mayor web de viajes del mundo, que ayuda a los viajeros aprovechar el máximo potencial de cada viaje». Se distinguen tres grandes grupos o generaciones que, en cierta manera, permiten establecer ciertos paralelismos con las tipologías previamente descritas. Nos encontramos, por tanto, con los millenials (18-34 años), la generación $X$ (35-64 años) y los baby boomers (65 años y +), sus motivaciones, hábitos de consumo, intereses, niveles de gastos, etc...son totalmente diferentes, como también lo son el uso y demanda de las TIC a la hora de organizar sus viajes. El TripBarometer 2016, "Traveler trends and motivations globals findings» recogía seis personalidades entre los usuarios de su web, de acuerdo a las actitudes, la edad, preferencias de reserva y sus ingresos.

1) Los que buscan buena relación calidad-precio: a menudo viajan con niños, tienen ingresos medios y se identifican con el grupo de edad de 25 a 34. Tienden a usar el móvil, buscan ofertas y los destinos seleccionados suelen ser de sol y playa.

2) Los viajeros de lujo: tienen ingresos altos, viajan con su pareja y se encuadran en el grupo de edad de 25 a 49 años. Sus preferencias en cuanto a destinos suelen ser, calurosos y soleados, fundamentalmente destinos urbanos y de sol y playa. Valoran las opiniones vertidas por otros usuarios a la hora de hacer sus elecciones.

3) Los viajeros sociales: viajan con familiares o grupos de amigos, les influye mucho el «boca a boca», tienen ingresos medios o altos, suelen pertenecer al grupo de edad comprendida entre los 25-49 años y eligen destinos predominantemente de sol y playa.

4) Los viajeros independientes: suelen viajar solos, prefieren canales de comercialización independientes, eligen sus destinos motivados por la cultura, no por el clima, y sus niveles de ingresos pueden ser 
Actas del Seminario Internacional Destinos Turísticos Inteligentes:

nuevos horizontes en la investigación y gestión del turismo

Universidad de Alicante, 26 y 27 de octubre de 2017

altos, identificándose con grupos de edades más adultos, frente a aquellos que buscan experiencias más económicas, acordes a sus posibilidades, que suelen ser turistas más jóvenes. Hacen uso de las redes sociales, además de para obtener recomendaciones, compartir sus experiencias.

5) Los investigadores: son turistas que emplean mucho tiempo en el proceso previo de organización del viaje, buscando destinos, actividades, restaurantes y alojamientos. Suelen tener ingresos medios-altos, viajan en pareja y se encuadran entre la denominada generación $X$.

6) Los viajeros habituales: son turistas que suelen repetir destino, asocian la práctica turística más que con el conocimiento con el descanso y relajación, tienden a tener ingresos no excesivamente altos y se identifican con grupos de edad más longevos.

Los resultados de este tipo de informes contribuyen en el conocimiento de los heterogéneos perfiles del visitante del siglo XXI, si bien, hay que tener en cuenta el sesgo que llevan implícito, al tratarse de una encuesta realizada a los usuarios de ese portal web ${ }^{4}$. Es innegable que muchos son los matices que se pueden incluir a la hora de investigar sobre las características del visitante en la era de la revolución tecnológica, pero hay una serie de aspectos en los que coinciden numerosos profesionales del sector, y que se sintetiza en 5 tips la consultora Cognodata Consulting:

4. El estudio de TripBarometer 2016 recoge los resultados de la encuesta realizada entre el 21 de junio y el 8 de julio de 2016. Se elaboraron 36.444 entrevistas en 33 mercados distribuidos en 7 regiones geográficas. La muestra se compone de los usuarios del sitio web de TripAdvisor que buscaron información online para realizar viajes en la anualidad pasada. 
Actas del Seminario Internacional Destinos Turísticos Inteligentes: nuevos horizontes en la investigación y gestión del turismo

Universidad de Alicante, 26 y 27 de octubre de 2017

Tabla 2: Aspectos del Turista 3.0

Conectado y actualizado: Son personas que están conectadas las 24 horas a través de su smartphone, dispositivo desde el que visitan webs, se mueven y comparten contenido en redes sociales y realizan transacciones. Son personas que están al día de las ofertas, reservas y destinos. Comparten sus experiencias a través de las redes sociales, por lo que Facebook, Twitter, Instagram son sus medios naturales de información y opinión.

"Recomendado», recomienda y se deja recomendar: A la hora de elegir un viaje lo que más tienen en cuenta por encima de otros factores es los comentarios que han realizado otros usuarios, por ello, antes de contratar un viaje, buscan información en redes sociales a través de los diferentes medios y realizan la mejor elección en función de lo que opinen otros usuarios.

Influyente: tienen a su alcance mucha tecnología, por eso los comentarios que publican pueden influir en futuras decisiones de viajeros, ya que estos comentarios pueden ser positivos o negativos en función de su experiencia propia. Esto exige a las empresas del sector turístico optimizar la experiencia de cliente, cuidando de forma personalizada a los viajeros y manteniéndose al tanto de sus comentarios en redes sociales.

Concienciado: el viajero cada vez está más concienciado con la responsabilidad social. El smartphone es una herramienta clave para cuidar el medio ambiente, ya que evita la necesidad de imprimir documentación, permitiendo realizar las reservas de sus viajes de forma digital, acceder a las facturas online, o llevar los billetes en el móvil.

Alternativo: no son personas que atienda a las formas clásicas de viajar, sino que están abierto a nuevas experiencia y modalidades de viaje como las que les ofrece la economía colaborativa. Las plataformas de intercambio y compartición de servicios o las guías online construidas con la aportación de los usuarios son algunos ejemplos de esta tendencia.

Fuente: González, L. (2017) Cinco características que diferencian al turista 3.0. [Recuperado de http://www.cognodata.com/notas_de_prensa/cinco-caracteristicas-que-diferencian-alturista-3-0/]

Teniendo en cuenta estas premisas, trataremos de conocer el perfil del visitante en un destino Patrimonio de la Humanidad (UNESCO) como es Ávila, destino piloto en el proyecto de investigación anteriormente mencionado.

\section{Breve caracterización del destino Ávila: smart heritage city}

Los destinos patrimoniales se han convertido en las últimas décadas en lugares de turismo de masas (Troitiño Vinuesa; Troitiño Torralba, 2016). El carácter mixto de la visita ha derivado en la llegada de perfiles heterogéneos a lugares que a priori se asociaban a prácticas motivacionales de índole cultural. Lo cierto es que, en ese proceso de conversión en destino turístico, la recuperación y puesta en valor, cultural y turística, de sus elementos 
Actas del Seminario Internacional Destinos Turísticos Inteligentes:

nuevos horizontes en la investigación y gestión del turismo

Universidad de Alicante, 26 y 27 de octubre de 2017

monumentales ha sido clave, si bien, esta circunstancia no está exenta de dificultades, dado que, en ocasiones, se produce un cierto olvido de otro tipo de dimensiones que son claves para el equilibrio de las ciudades/destinos, tales como las urbanísticas, sociales, funcionales y paisajísticas (Troitiño Vinuesa; Troitiño Torralba, 2009).

El turismo es una actividad que da visibilidad a la dimensión económica del patrimonio ya que su conservación, promoción y puesta en valor se realiza, en cierta manera, con el objetivo de rentabilizar al máximo su valor, abriendo el debate sobre el impacto de la cultura en el turismo (OCDE, 2009), y viceversa, la huella del turismo en la cultura y en el territorio. Desde una lectura turística, los bienes incluidos en la Lista del Patrimonio Mundial, como es el caso de Ávila, se han visto beneficiados dado que en muchos casos, este reconocimiento no solo ha supuesto su revalorización cultural, sino que también ha contribuido a posicionarlos en el mapa turístico internacional, lo que ha provocado ciertas contradicciones, surgiendo toda una serie de conflictos derivados de los procesos e impactos que el turismo desencadena y que no son fáciles de controlar (Lazzarotti, 2000).

La situación actual evidencia que las ciudades Patrimonio de la Humanidad, por su singularidad patrimonial, tienen cada día una función turística más significativa y el turismo constituye uno de los pilares fundamentales de su economía. Los riesgos de la de presión turística, en espacios de cierta fragilidad, y la debilidad o carencias en cuanto a las medidas de control y gestión del turismo, ponen de manifiesto la necesidad de superar la fase estrictamente promocional y apostar por modelos de desarrollo sostenibles que lo integren plenamente en la vida de la ciudad (Troitiño, 2002; Exceltur, 2017), y en ese sentido se orientan los objetivos asociados a los Destinos Turísticos Inteligentes (INVAT·TUR, 2015).

Ávila es uno de los destinos patrimoniales que forma parte de un grupo singular dentro de las ciudades históricas españolas. En el marco estructural de la Organización de las Ciudades de Patrimonio Mundial (OCPM) se constituyó, en 1993, el Grupo de Ciudades Patrimonio de la Humanidad de España, formado en primera instancia por seis ciudades, Ávila, Cáceres, Salamanca, Santiago de Compostela, Segovia y Toledo, en 1996, se incorporó Córdoba, en 1998, lo haría Cuenca, seguida de Alcalá de Henares en 2000, San Cristóbal de La Laguna e Ibiza en 2002, Tarragona y Mérida en 2006, y finalmente en 2014, Úbeda y Baeza. Esta alianza, tenía entre sus objetivos, el actuar como reclamo turístico, por ello en el año 2003 se firmó con la Secretaría 
Actas del Seminario Internacional Destinos Turísticos Inteligentes:

nuevos horizontes en la investigación y gestión del turismo

Universidad de Alicante, 26 y 27 de octubre de 2017

General de Turismo un «acuerdo marco de cooperación para el desarrollo y la promoción turística del Grupo Ciudades Patrimonio de la Humanidad de España», tanto a nivel nacional como internacional (Troitiño Vinuesa; Troitiño Torralba, 2009). Sin duda, las ciudades del Grupo han realizado durante los últimos años un importante esfuerzo en materia de recuperación patrimonial y puesta en valor turística de sus recursos, así como notables mejoras en la adecuación para la visita pública, e importantes cambios en los modelos tradicionales de gestión turística (Calle; García, 2016)

En este sentido, Ávila ${ }^{5}$, es uno de los destinos que ha conocido un significativo desarrollo turístico en las dos últimas décadas, pasando de los 300.000 visitantes anuales estimados a mediados de los 90 del s. XX, a rondar el millón con motivo de la celebración del $V$ Centenario del nacimiento de Santa Teresa en 2015. La oferta abulense se ha ido adaptando a las necesidades de la demanda, y uno de los sectores que ha experimentado un mayor incremento ha sido el del alojamiento, pasando de las 558 plazas en 1991 a las 2.690 en 2017 (Ayto. de Ávila, 2002a; 2016b).

La dinámica como destino de Ávila ha ido de la mano de la política turística a nivel nacional y autonómica (Plan Futures II, Plan Integral de Calidad del Turismo Español (PICTE), Plan Horizonte 2020, Plan Nacional Integral de Turismo 2012-2015, Plan Estratégico de Turismo de Castilla y León 20142018, Plan de Marketing turístico de Castilla y León 2013-204, Plan Integral de Promoción turística internacional de Castilla y León 2017...) y fundamentalmente de la local (Plan de Excelencia Turística 1999-2004, Sicted, Ávila Accesible, Plan Estratégico de Turismo 2015, Plan de Gestión de la ciudad antigua de Ávila y sus iglesias extramuros 2010, Programas ARI...) y acorde a las mejoras implementadas en las infraestructuras de gestión locales (Tenencia de Alcadía Servicios a la Ciudad-Turismo y Patrimonio Histórico, Centro de Recepción de Visitantes, Observatorio Turístico...)

5. Declarada Conjunto Histórico en 1982 (Real Decreto 3940/1982 de 15 de diciembre) e inscrita en 1985 en la Lista de Patrimonio Mundial de la UNESCO cumpliendo los criterios: (iii): Aportar un testimonio único, o por lo menos excepcional, de una civilización que desapareció1 «Por ser un ejemplo de ciudad fortificada, que ha conservado íntegramente su muralla. La densidad de monumentos civiles y religiosos intramuros y extramuros hacen de ella un ejemplo de extraordinario valor»; (iv): Ser un ejemplo sobresaliente de un tipo de construcción, de un conjunto arquitectónico que ilustre una etapa significativa de la historia. Por ser un ejemplo de repoblación emprendida por el Reino de Castilla tras la reconquista de Toledo. Destacando el marcado carácter medieval de la Ciudad de Ávila, compaginando tanto aspectos religiosos como defensivos» 
Actas del Seminario Internacional Destinos Turísticos Inteligentes:

nuevos horizontes en la investigación y gestión del turismo

Universidad de Alicante, 26 y 27 de octubre de 2017

Figura 2: Vista aérea de Ávila y principales elementos monumentales de la ciudad

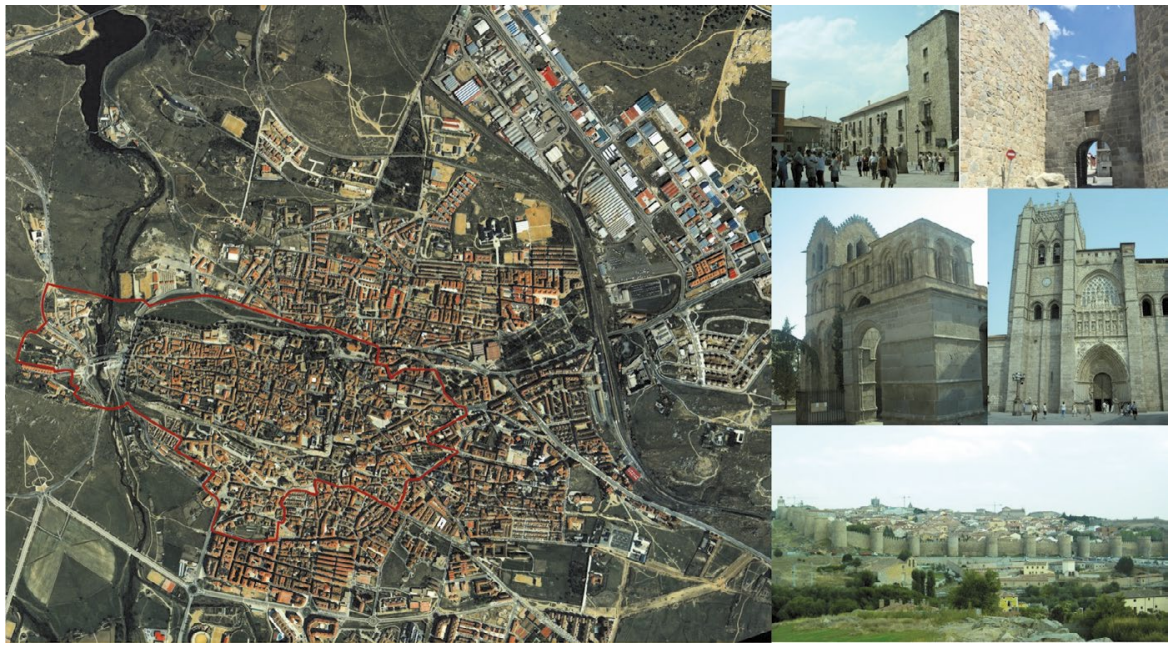

Fuente: (imagen aérea) http://www.patrimoniocultural.jcyl.es/. Fotografías: Elaboración propia.

Ávila, ha pasado de ser un destino emergente a un destino patrimonial consolidado en el ámbito de la denominada región turística madrileña (Troitiño, 2010) y desde los últimos años viene trabajando para convertirse en uno de los Smart Heritage Destination de referencia en España. En este recorrido, la ciudad se incorpora a la Red Española de Ciudades Inteligentes (RECl) en 2013, con el «objetivo de intercambiar experiencias y trabajar conjuntamente para desarrollar un modelo de gestión sostenible y mejorar la calidad de vida de los ciudadanos, incidiendo en aspectos como el ahorro energético, la movilidad sostenible, la administración electrónica, la atención a las personas o la seguridad». (Ayto. Ávila. Smart City, 2017)

En materia turística, poco a poco se están implementando medidas puntuales, tales como mejoras en la iluminación de los monumentos, la creación de aplicaciones para el visitante (Ayto. Ávila. Ávila Turismo, 2017), la gestión integrada de entradas a monumentos y registros de visitantes en los servicios de información turística, o la creación de puntos wi-fi. Sin embargo, las sinergias que surgen entre el destino inteligente y el patrimonio cultural, 
Actas del Seminario Internacional Destinos Turísticos Inteligentes:

nuevos horizontes en la investigación y gestión del turismo

Universidad de Alicante, 26 y 27 de octubre de 2017

dependen de lecturas mucho más amplias y complejas de la realidad urbana y territorial (Troitiño; García, 2016).

En destinos patrimoniales españoles, las iniciativas que se están desarrollando en la lógica de los DTI, en su gran mayoría, no se están acometiendo en clave de destino, sino de manera singular, especialmente sobre monumentos y orientándose más a aspectos de conservación que de uso turístico, como es el caso del proyecto Smart Heritage, llevado a cabo por la Fundación Santa María la Real, que tuvo como objeto de estudio la catedral y la muralla de Ávila.

Como continuidad de esta iniciativa, se pone en marcha, en el marco del programa Interreg Sudoe ${ }^{6}$, el proyecto Smart Heritage City, en el que Ávila es el destino piloto seleccionado en nuestro país. Tal y como recoge la Fundación Santa María del Real (parr.1), ente coordinador, «se basa en el diseño e implementación de un conjunto de herramientas desarrolladas mediante el uso de las TIC y el conocimiento experto de diferentes campos relacionados con la gestión del patrimonio a escala urbana, con el objetivo de extender el concepto de Smart City a Smart Heritage City adaptando la escala de monitorización, pasando de un edificio a un conjunto urbano».

6. El Programa Interreg Sudoe apoya el desarrollo regional en el sudoeste de Europa financiando proyectos transnacionales a través del Fondo Europeo de Desarrollo Regional (FEDER). El Programa promueve la cooperación transnacional para resolver problemas comunes a las regiones del sudoeste europeo, como la baja inversión en investigación y desarrollo, la baja competitividad de la pequeña y mediana empresa y la exposición al cambio climático y a riesgos ambientales. http://www.interreg-sudoe.eu/inicio 
Actas del Seminario Internacional Destinos Turísticos Inteligentes: nuevos horizontes en la investigación y gestión del turismo

Universidad de Alicante, 26 y 27 de octubre de 2017

Tabla 3: Smart Heritage City. Objetivos y resultados del proyecto

\begin{tabular}{|c|c|}
\hline Objetivos & Resultados esperados \\
\hline $\begin{array}{l}\text { - Crear una solución tecnológica de código } \\
\text { abierto para la gestión y mantenimiento } \\
\text { de centros urbanos históricos que } \\
\text { integre datos recogidos por redes de } \\
\text { sensores desplegados en el conjunto } \\
\text { urbano, para controlar y dar respuesta } \\
\text { a los elementos de riesgo naturales y } \\
\text { antrópicos que afectan a los edificios y } \\
\text { a su entorno, la gestión de consumos } \\
\text { energéticos y ordenar el flujo de } \\
\text { visitantes. } \\
\text { - Generar una herramienta tecnológica } \\
\text { basada en las necesidades de los cascos } \\
\text { históricos (conservación, seguridad, } \\
\text { eficiencia energética) que será } \\
\text { exportable y aplicable a todo el espacio } \\
\text { SUDOE y el resto de Europa. }\end{array}$ & $\begin{array}{l}\text { - Una infraestructura versátil de captación } \\
\text { y almacenamiento de los datos, que } \\
\text { integrará sistemas de monitorización y } \\
\text { actuación correspondientes a distintas } \\
\text { plataformas tecnológicas. } \\
\text { - Una aplicación software destinada a los } \\
\text { turistas, con un enfoque de divulgación } \\
\text { y conservación preventiva de los } \\
\text { elementos patrimoniales. } \\
\text { - Una herramienta software de gestión } \\
\text { inteligente y toma de decisiones (SHCity- } \\
\text { Gestor), en formato Open Source, } \\
\text { desarrollada a partir de la infraestructura } \\
\text { de captación de datos y la integración } \\
\text { del conocimiento experto en tecnología } \\
\text { y protección del patrimonio. }\end{array}$ \\
\hline
\end{tabular}

Fuente: Smart Heritage City. European Regional Development Fund. 2016. http://shcity.eu/

Figura 3: Ávila. Estudio de caso del proyecto Smart Heritage City

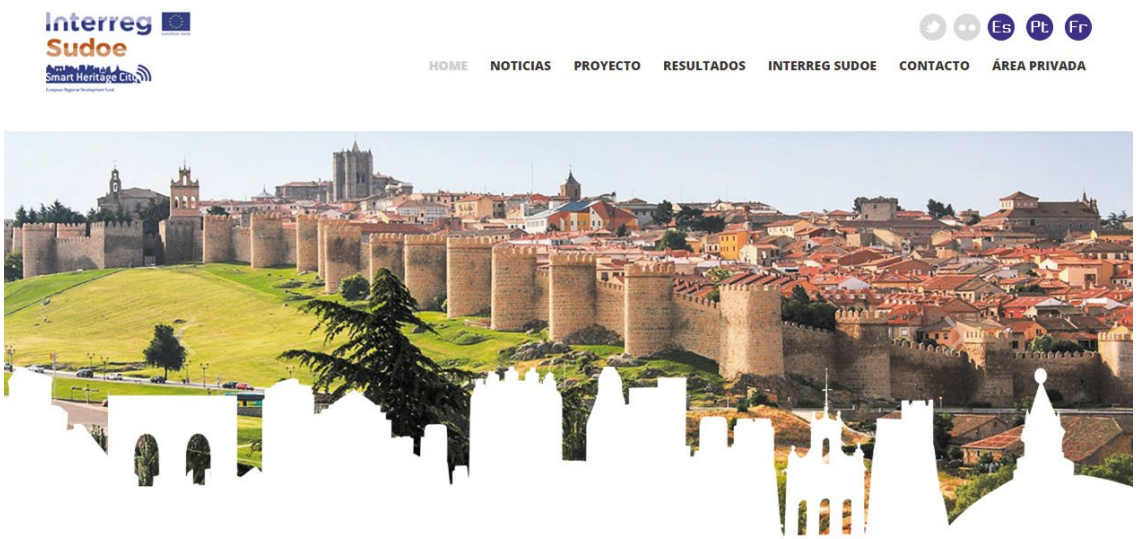

Fuente: Smart Heritage City. European Regional Development Fund. 2016. http://shcity.eu/

Se trata de un proyecto ambicioso que, de partida, plantea una serie limitaciones que complican un desarrollo de las acciones más dinámico, como 
Actas del Seminario Internacional Destinos Turísticos Inteligentes:

nuevos horizontes en la investigación y gestión del turismo

Universidad de Alicante, 26 y 27 de octubre de 2017

son la falta de planes de gestión integral, el desconocimiento por parte de los gestores del patrimonio (Administraciones Públicas principalmente) de las tecnologías disponibles, la falta de inversión pública y privada, la escasa formación y ausencia de estrategias políticas comunes, la sobrecarga procedente del turismo, problemas en materia de conservación y desconocimiento sobre las consecuencias que tiene el uso intensivo en los edificios patrimoniales y en su entorno, que hacen que lugares con un gran interés cultural resulten dañados y descuidados, el despoblamiento de los centros históricos, la transformación de usos y la pérdida de actividad económica en los mismos, la falta de planes que vinculen la gestión del Patrimonio con el desarrollo local, etc...

De lo anteriormente expuesto se deduce, que proyecto Smart city y Smart Destination están interrelacionados y qué efectivamente, una buena gestión de la realidad local en sus múltiples dimensiones incidirá de manera favorable en la conversión de Ávila en un destino de calidad. En todo territorio turístico el epicentro es el visitante, por tanto, ¿̇cuál es el perfil de aquellos que llegan a Ávila?

\section{El perfil del visitante en la ciudad de Ávila}

El Plan de Excelencia Turística desarrollado entre los años 1999-2004 supuso un punto de inflexión para la ciudad en clave turística. Comenzó a trabajarse en la idea de destino y esto supuso la necesidad de indagar sobre las características básicas de los visitantes que llegaban a la capital abulense. El primer estudio sobre afluencia y perfil de los visitantes se llevó a cabo entre el año 2000 y 2001 (Troitiño; García; Calle, 2002), parte de la investigación se elaboró a partir de los resultados obtenidos tras la realización de encuestas tanto a visitantes individuales como a aquellos que viajaban en grupos organizados. Sin embargo, este informe no fue el único efectuado. La puesta en marcha del Observatorio Turístico de la ciudad en 2002, todavía hoy vigente, supuso la creación de un instrumento de medición y análisis permanente de la situación turística de la ciudad. La recopilación de información referida a todas las variables que configuran el sistema turístico urbano, ha permitido, durante más de dos décadas, generar una rica base de datos a partir de la cual obtener un diagnóstico que ayude a los gestores en la toma de decisiones.

Desde entonces se han implementado diversas encuestas de coyuntura a la demanda, prestando especial atención a aquellos momentos de 
Actas del Seminario Internacional Destinos Turísticos Inteligentes:

nuevos horizontes en la investigación y gestión del turismo

Universidad de Alicante, 26 y 27 de octubre de 2017

cierta relevancia turística en la ciudad, tales como el Mercado Medieval o las ediciones de las Exposiciones de Edades del Hombre, todas ellas con el propósito de conocer en detalle no solo los aspectos básicos, motivaciones, percepciones y valoraciones, pautas de consumo y comportamiento en destino...sino para determinar cómo ha ido cambiando la demanda, para así, desde el ámbito político, perfilar estrategias orientadas a captar nuevos nichos de mercado no presentes en Ávila.

Refiriéndonos a la encuesta realizada en 20047, año excepcional en la ciudad pues tuvo lugar en la catedral la exposición de Testigos (859.859 visitantes), y prestando atención al visitante individual, el perfil de la demanda respondía a un predominio del visitante de origen nacional (86\%) frente al extranjero, fundamentalmente procedentes de provincias limítrofes: los madrileños y castellano-leoneses suponían al $47,46 \%$ del total de visitantes encuestados. Según la forma de organizar el viaje en un $87 \%$ los visitantes de Ávila llegaban a la ciudad en viaje organizado por cuenta propia.

El porcentaje de excursionismo era bastante considerable, representaba el $66 \%$. La duración media de los visitantes que pernoctan era de 2,42 noches. Los visitantes que acudían a la ciudad especialmente motivados por la visita a la exposición (24,34\%), pero el motivo principal de su visita era el conocimiento de la ciudad en general $(33,61 \%)$ y «pasar el día» $(12,55 \%)$.

Había un alto porcentaje de visitantes que asociaba Ávila con las imágenes turísticas más tradicionales como la Muralla y la figura de Santa Teresa, y también era importante el número de personas que ya identificaban la condición de Ávila como «Ciudad Patrimonio de la Humanidad». Una de las cuestiones que llama la atención de los resultados obtenidos entonces y que más nos interesan, dado el objetivo de la presente comunicación, es el escaso protagonismo que tenía Internet como herramienta de búsqueda o de referencia para obtener información del destino, tan solo representaba un $17 \%$, mientras que el visitante acudían a la ciudad fundamentalmente por interés propio $(81,90 \%)$ y el $26 \%$ por recomendación de familiares o amigos.

7. Tomamos de referencia esta encuesta para ver los resultados con cierta distancia temporal y evaluar a posteriori los cambios que se han producido en la demanda vinculados al uso de los dispositivos móviles. Ficha técnica de la encuesta: personas no residentes en la ciudad de Ávila que visitan el destino con motivación turística. Se supone infinita. Tamaño de la muestra: 1.498. Nivel de confianza: 95,5\%. Error muestral: 3\% 
Actas del Seminario Internacional Destinos Turísticos Inteligentes: nuevos horizontes en la investigación y gestión del turismo

Universidad de Alicante, 26 y 27 de octubre de 2017

Tabla 4: Características básicas de la demanda en la ciudad de Ávila en 2004

\begin{tabular}{|c|c|c|c|}
\hline \multicolumn{4}{|c|}{ TIPOLOGÍA DE VISITANTES (perfil de la demanda) } \\
\hline MOTIVO PRINCIPAL DE LA VISITA & & PROCEDENCIA DE LOS VISTIANTES & \\
\hline Visitar la Exposición TESTIGOS & 24,34 & Extranjeros & 14,02 \\
\hline Ver la Muralla & 4,25 & Visitantes proximidad (Madrid y CyL) & 47,46 \\
\hline Visitar los lugares asociados a Sta. Teresa & 2.51 & Resto de España & 38,32 \\
\hline Visitar a familiares $\mathrm{y} / \mathrm{o}$ amigos & 8,30 & GRUPOS DE EDAD & \\
\hline Visitar los monumentos y museos de la ciudad & 6,42 & Menos de 19 años & 2,58 \\
\hline Conocer Ávila en general & 33,61 & De 20 a 30 años & 26,43 \\
\hline Trabajo, negocios o motivos profesionales & 3,63 & De 30 a 40 años & 24,62 \\
\hline Simplemente pasar el dia & 12,55 & De 40 a 50 años & 22,59 \\
\hline Estudios o asistencia a cursos & 2,79 & De 50 a 65 años & 17,50 \\
\hline Otros & 1.60 & Mayor de 65 años & 6,28 \\
\hline DURACIÓN DE LA ESTANCIA EN ÁVILA & & NIVEL DE ESTUDIOS & \\
\hline Unas horas & 21,01 & Sin estudios & 2,96 \\
\hline Un dia & 44,56 & Estudios primarios & 10,11 \\
\hline Pernocta en la ciudad & 34,43 & Estudios secundarios & 29,30 \\
\hline DURACIÓN DE LA ESTANCIA (turistas que pernoctan) & & Estudios universitarios & 53,51 \\
\hline 1 noche & 27,00 & Otros & 4,13 \\
\hline 2 noches & 48,20 & CATEGORÍAS SOCIOPROFESIONALES & \\
\hline 3 noches & 13,80 & Amas de casa, jubilados y parados. & 16,85 \\
\hline Más de 3 noches & 11,00 & Empleados administrativos & 14,44 \\
\hline Duración media & 2,42 & Empleados servicios de baja cualificación & 10,36 \\
\hline TIPO DE ALOJAMIENTO (turistas que pernoctan) & & Estudiantes & 15,83 \\
\hline Hotel & 46,02 & Ocupados superiores & 30,63 \\
\hline Hostal o pensión & 21,46 & Trabajadores manuales & 8,83 \\
\hline Camping & 0,66 & Otros & 3,06 \\
\hline Casa de familiares/amigos & 26,77 & TIPO DE GRUPO DE VIAJE (visit. individuales) & \\
\hline Otros (residencias religiosas,etc...) & 5,09 & Familia nuclear & 18,77 \\
\hline VISITA A OTROS DESTINOS EN EL DÍA & & Pareja & 55,86 \\
\hline No va a visitar otros lugares & 83,42 & Grupo de amigos & 20,88 \\
\hline Si va a visitar otros destinos & 16,58 & Familia extensa & 1,56 \\
\hline MEDIO DE TRANSPORTE (visitantes individuales) & & Familia y amigos & 2,93 \\
\hline Vehículo propio & 72,15 & TIPO DE GRUPO DE VIAJE (visit. en grupo) & \\
\hline Autobús de línea regular & 10,80 & Grupo organizado de agencia & 36,97 \\
\hline Tren & 13,18 & Grupo escolar & 23,43 \\
\hline Otros & 3,87 & Tercera Edad & 25,52 \\
\hline FORMA DE ORGANIZAR EL VIAJE & & Asociaciones & 2,08 \\
\hline Viaje por cuenta propia (visitantes individuales) & 86,78 & Grupos de turismo religioso & 10,41 \\
\hline Viaje en grupo organizado (visitantes en grupo) & 13,22 & Otros & 1,56 \\
\hline \multicolumn{4}{|c|}{ IMÁGENES Y VALORACIONES DE LA CIUDAD } \\
\hline $\begin{array}{l}\text { RAZONES PARA LA ELECCIÓN DE LA CIUDAD } \\
\text { COMO DESTINO TURÍSTICO (respuesta múltiple) }\end{array}$ & & INFORMACIÓN UTILIZADA (respuesta múltiple) & \\
\hline Interés propio & 81,26 & Ninguna & 43,96 \\
\hline Recomendación de amigos o familiares & 32,79 & Folletos de la Oficina de Información Turística & 29,55 \\
\hline Recomendación agencia de viajes & 1,80 & Otros folletos turísticos & 9,55 \\
\hline Catálogos TாOO & 2,88 & Guias de viaje & 15,50 \\
\hline Folletos furisticos & 7,39 & Estudios sobre Ávila, Santa Teresa, etc & 1,44 \\
\hline Anunciosen nrensa & 126 & Internet & 30,63 \\
\hline Internet & 16,76 & Ditros & 2,70 \\
\hline Experiencia previa de un viaje anterior & 19,82 & & \\
\hline
\end{tabular}

Fuente: Boletín n.o 7. Observatorio Turístico de la ciudad de Ávila. 2005

Tras una década de avances en la tecnología y cambios sustanciales en el sector turístico, ¿qué cambios se han producido en la demanda en Ávila?, 
Actas del Seminario Internacional Destinos Turísticos Inteligentes:

nuevos horizontes en la investigación y gestión del turismo

Universidad de Alicante, 26 y 27 de octubre de 2017

¿qué tipo de visitantes predomina en este destino?, millenials, generación $X$, baby boomers, ¿qué protagonismo tiene internet a la hora de preparar el viaje?, ¿ ha cambiado el perfil y las imágenes turísticas con las que el visitante asocia Ávila? Para dar respuesta a estas cuestiones y en el marco del proyecto de investigación dentro del Programa Estatal de I+D+i, Ministerio de Economía y Competitividad, se llevó a cabo un cuestionario ${ }^{8}$ que constaba de 16 preguntas, abiertas y cerradas, que se estructuraban de acuerdo a seis bloques: I. Tecnología y viaje; II. Inspiración y búsqueda. III. Comparación y reserva. IV. Experiencia. V. Compartición. VI. Perfil del visitante. Se realizaron 400 encuestas, a pie de calle entre los meses de julio y octubre, tanto en días laborables, como festivos y fines de semana. Una vez validados los cuestionarios, se consideraron 336 encuestas. A continuación, se expondrán algunos de los resultados más significativos extraídos para cada uno de los bloques citados:

\subsection{Tecnología y viaje}

Se busca obtener la información referida a tres cuestiones fundamentales, la primera de ellas centrada en la influencia de las RR.SS. (butterfly effect"), Vargas-Sánchez, 2016) en la toma de decisión a la hora de elegir un destino turístico. En segundo lugar, que rol adquieren las tecnologías a la hora de organizar el viaje y la importancia de la seguridad en la red y, por último, el grado de innovación que el visitante percibe sobre el destino. Siguiendo la escala de Likert de 1 a 5 (siendo 1 totalmente en desacuerdo; 2 en desacuerdo; 3 ni de acuerdo ni en desacuerdo; 4 de acuerdo; y 5 totalmente de acuerdo), los resultados nos muestran que, para el visitante actual en la ciudad, las tecnologías son una herramienta útil en los viajes $(4,42)$, denotan una especial preocupación por las cuestiones relacionadas con la ciberseguridad $(4,02)$ y valoran muy positivamente que el destino innove y facilite el uso de las tecnologías para mejorar la calidad de la experiencia en el lugar $(4,13)$.

8. Para la obtención de datos se diseñó un cuestionario estándar que, posteriormente, se adaptó a las necesidades de cada destino, con el fin de que fuera lo más fiel posible a las especificidades de cada uno de ellos, y los resultados obtenidos arrojaran información fidedigna del perfil del visitante actual, en el caso que nos ocupa, de Ávila. Se realizaron 400 encuestas, de las cuales, finalmente fueron válidas 336. 
Actas del Seminario Internacional Destinos Turísticos Inteligentes: nuevos horizontes en la investigación y gestión del turismo Universidad de Alicante, 26 y 27 de octubre de 2017

Tabla 5: Aspectos relacionados con el uso de las nuevas tecnologías en la organización del viaje

\begin{tabular}{|l|c|}
\hline & Grado de acuerdo \\
\hline $\begin{array}{l}\text { p.1. Lo que veo en las redes sociales influye en mi opinión sobre un } \\
\text { destino turístico }\end{array}$ & 3,43 \\
\hline $\begin{array}{l}\text { p.2. Las tecnologías me ayudan a tener una experiencia más } \\
\text { satisfactoria como turista }\end{array}$ & 3,85 \\
\hline p.3. Las tecnologías son parte fundamental de mis viajes & 3,26 \\
\hline p.4. Las tecnologías son una herramienta útil en mis viajes & 4,42 \\
\hline $\begin{array}{l}\text { p.5. Me preocupa que una empresa pueda registrar y guardar mi } \\
\text { actividad en mi destino turístico }\end{array}$ & 4,02 \\
\hline $\begin{array}{l}\text { p.6. Dejaría que las empresas turísticas obtuvieran mis datos } \\
\text { personales a cambio de ofertas, descuentos o servicios personalizados }\end{array}$ & 1,98 \\
\hline $\begin{array}{l}\text { p.7. Valoro positivamente que el destino trate de innovar y utilizar las } \\
\text { tecnologías para mejorar mi experiencia }\end{array}$ & 4,13 \\
\hline $\begin{array}{l}\text { p.8. Confío en lo que otros usuarios opinan en portales como } \\
\text { Tripadvisor o Booking }\end{array}$ & 3,68 \\
\hline p.9. Ávila en un destino que respeta el medio ambiente & 4,02 \\
\hline $\begin{array}{l}\text { p.10 Ávila es un destino innovador. Siempre propone nuevas } \\
\text { experiencias al visitante }\end{array}$ & 2,80 \\
\hline
\end{tabular}

Fuente: Encuesta a visitantes. Destino piloto. Ávila. 2016. Proyecto de investigación «Nuevos enfoques para la planificación y gestión del territorio turístico: conceptualización, análisis de experiencias y problemas. Definición de modelos operativos para destinos turísticos inteligentes (TTI)». Ref-CSO2014-59193-R

Entre los aspectos menos considerados por los visitantes se encontraba la posibilidad de brindar información personal a cambio de posibles ofertas o promociones turísticas personalizadas $(1,98)$ y la percepción de Ávila como destino innovador $(2,80)$, la mayor parte de los encuestados desconocían de la existencia de aplicaciones turísticas y de puntos de acceso wi-fi libres en la ciudad. 
Actas del Seminario Internacional Destinos Turísticos Inteligentes:

nuevos horizontes en la investigación y gestión del turismo

Universidad de Alicante, 26 y 27 de octubre de 2017

Figura 4: TECNOLOGÍA Y VIAJE. Grado de acuerdo visitantes

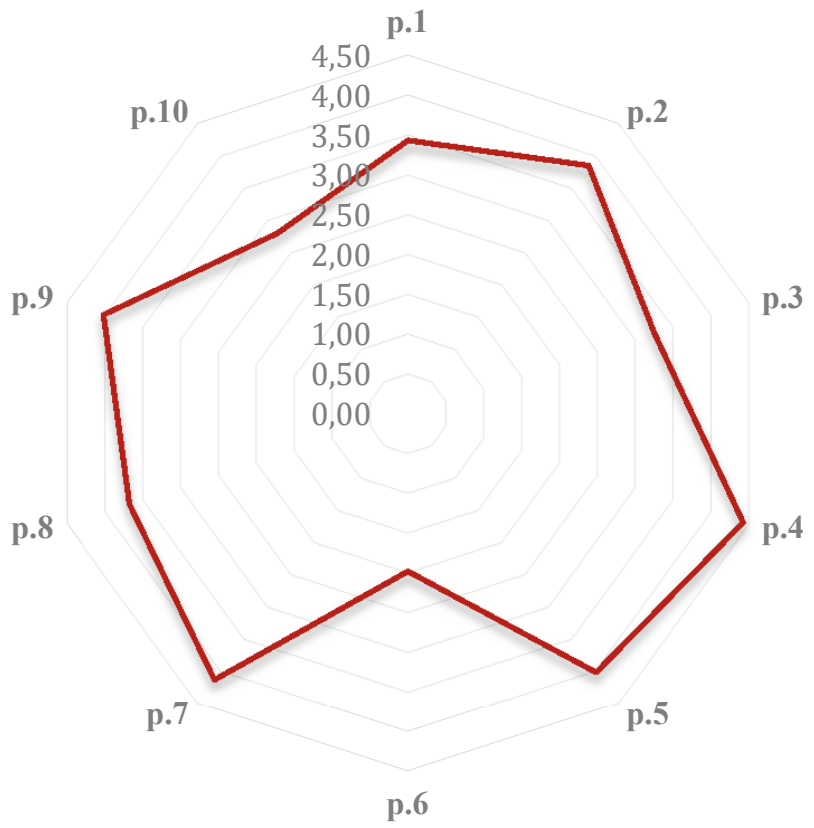

\subsection{Inspiración y búsqueda}

El reconocimiento de Ávila como Patrimonio Mundial (UNESCO) sigue siendo la principal inspiración para que el visitante acuda a la ciudad, de hecho, más de $37 \%$ de los encuestados así lo indicaba. Romper con la rutina habitual, $19,38 \%$, es otro factor relevante, especialmente si tenemos en cuenta los datos que se obtenían de la encuesta realizada por el Observatorio Turístico, que ponían de manifiesto el protagonismo del visitante de proximidad y el alto porcentaje de repetición de visita. 
Actas del Seminario Internacional Destinos Turísticos Inteligentes:

nuevos horizontes en la investigación y gestión del turismo

Universidad de Alicante, 26 y 27 de octubre de 2017

Figura 5: INSPIRACIÓN Y BÚSQUEDA. ¿Qué le inspiró a venir a Ávila?

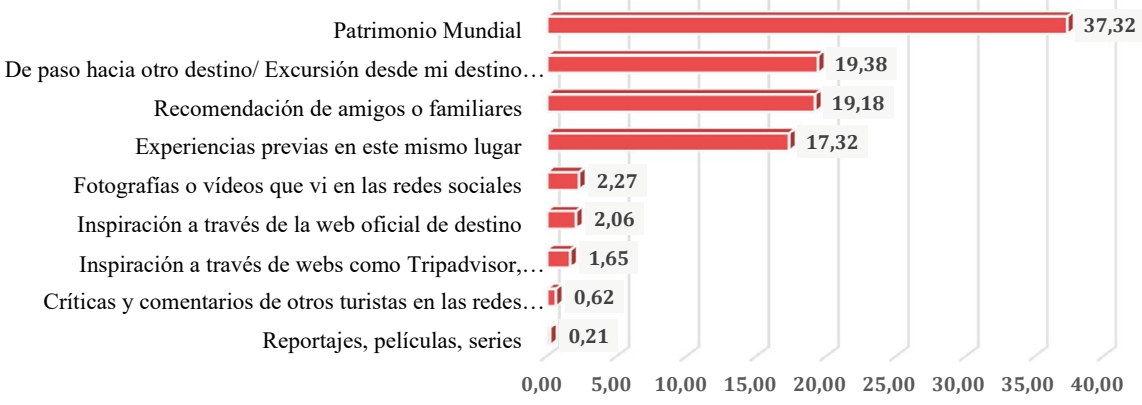

El visitante sigue identificando Ávila por sus atractivos culturales, de hecho, conocerlos representó para el 39,53\% el motivo principal del desplazamiento, seguido por su gastronomía $25,39 \%$ y por la cercanía al lugar de residencia $17,28 \%$. Otros aspectos tenían menos relevancia en la elección de la ciudad para ser visitada, aunque no por ello menos importantes a la hora de evaluar la calidad del destino en general, como es su tranquilidad $7,72 \%$, o la oferta de ocio y restauración $3,80 \%$. En este caso, los aspectos relacionados por portales turísticos web u opiniones vertidas en ellos por otros usuarios, apenas pesan como motivo de viaje.

Figura 6: INSPIRACIÓN Y BÚSQUEDA. Motivos por los que eligió Ávila como destino turístico (\%)

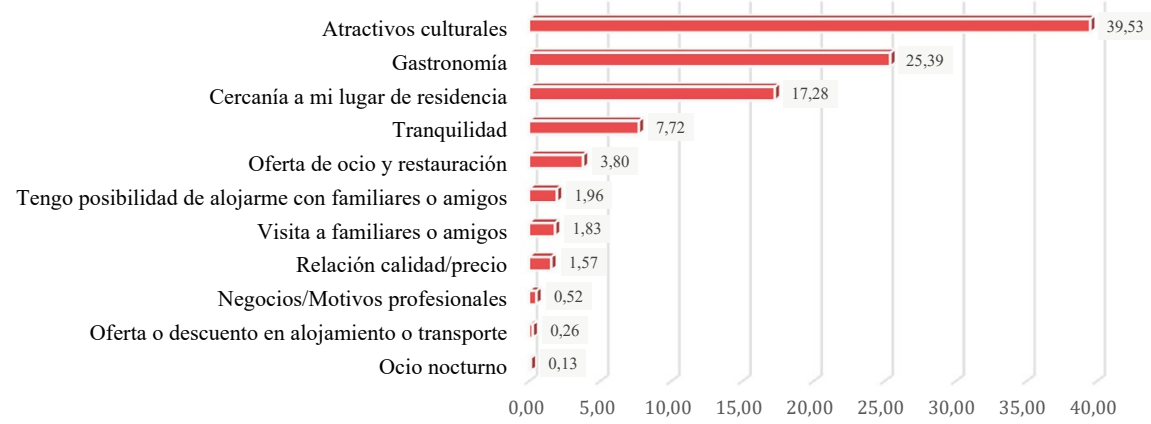


Actas del Seminario Internacional Destinos Turísticos Inteligentes:

nuevos horizontes en la investigación y gestión del turismo

Universidad de Alicante, 26 y 27 de octubre de 2017

\subsection{Comparación y reserva}

Las cuestiones consideradas en este apartado nos permiten determinar si el perfil del visitante de Ávila sigue asociándose al de excursionista, es decir, aquel que permanece unas horas en la ciudad y regresa a su domicilio o lugar de vacaciones a pernoctar, o bien, al de turista. Los datos obtenidos validan los ya registrados en encuestas previas, de hecho, el $62,20 \%$ de los encuestados no pernoctaba en la ciudad, frente al $37,80 \%$ que sí lo hacía.

Para aquellos que afirmaron dormir en la localidad, el $43,31 \%$ lo haría una noche, el $36,22 \%$ dos, lo que denota una estadía en la ciudad corta, tal y como también recoge la Encuesta de Ocupación Hotelera del Instituto Nacional de Estadística que la establece en 1,54 noches (INE, 2016).

Tabla 6: Duración de la estancia

\begin{tabular}{|l|c|c|}
\hline & Respuestas & $\%$ \\
\hline Una noche & 55 & 43,31 \\
\hline Dos noches & 46 & 36,22 \\
\hline Tres noches & 6 & 4,72 \\
\hline Cuatro noches & 2 & 1,57 \\
\hline s.d. & 18 & 14,17 \\
\hline Total & 127 & 100,00 \\
\hline
\end{tabular}

Fuente: Encuesta a visitantes. Destino piloto. Ávila. 2016. Proyecto de investigación «Nuevos enfoques para la planificación y gestión del territorio turístico: conceptualización, análisis de experiencias y problemas. Definición de modelos operativos para destinos turísticos inteligentes (TTI)». Ref-CSO2014-59193-R

La evolución de la demanda incide en las fórmulas de alojamiento elegidas en destino. En Ávila, sin embargo, entre los turistas, los establecimientos convencionales siguen siendo los más solicitados, el 70,87\% pernoctaron en hoteles de la ciudad, seguidos por $12,60 \%$ que lo hicieron en hostales o pensiones. El efecto de las denominadas plataformas $P 2 P$ en destinos patrimoniales de las características de Ávila es todavía muy incipiente, de hecho, apenas representaban el $2,36 \%$. 
Actas del Seminario Internacional Destinos Turísticos Inteligentes:

nuevos horizontes en la investigación y gestión del turismo

Universidad de Alicante, 26 y 27 de octubre de 2017

Figura 7: COMPARACIÓN Y RESERVA. Tipo de alojamiento (\%)

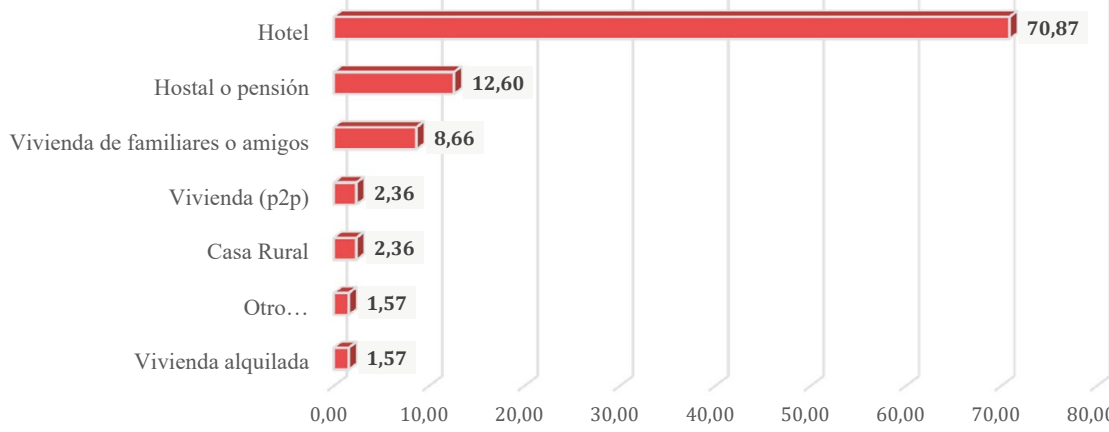

Mientras que no se evidencian cambios significativos en cuanto al tipo de alojamiento demandado por el visitante respecto a períodos temporales previamente estudiados, el modo de contratación sí que ha experimentado cambios notables, y es quizás, donde se más perceptible se hace el impacto de las nuevas tecnologías y plataformas en el sector turístico. La agencia de viajes física apenas tiene representatividad entre el visitante actual a la hora de hacer la reserva del viaje, tan solo un $1,57 \%$ de los encuestados recurrió a ellas, frente al $51,18 \%$ que hizo uso de las agencias on line, siendo el portal de reserva más utilizado, Booking (69,23\%).

Figura 8: COMPARACIÓN Y RESERVA. Canal por el que se hizo la reserva del alojamiento en Ávila. (\%)

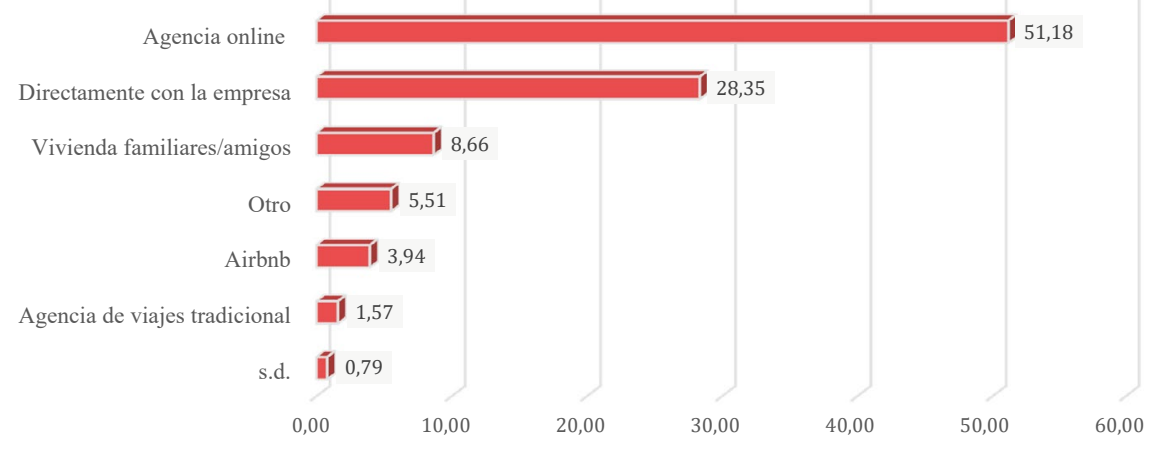


Actas del Seminario Internacional Destinos Turísticos Inteligentes:

nuevos horizontes en la investigación y gestión del turismo

Universidad de Alicante, 26 y 27 de octubre de 2017

Por último, dado que entre los motivos para visitar la ciudad se preguntaba por la cercanía a su lugar de residencia, queríamos conocer el grado de repetición de la visita y poder medir así la fidelización al destino. Para el 58,33\% de los encuestados era la primera vez que iban a Ávila, frente al $41,67 \%$, que ya lo había hecho en alguna otra ocasión.

\subsection{Experiencia}

A lo largo de la comunicación hemos puesto de manifiesto la importancia que las tecnologías y dispositivos tecnológicos han adquirido entre los visitantes, prueba de ello, es que el $77,77 \%$ de los encuestados usaba su smartphone cuando viajaba, un 13,91\%, la tablet, un 4,32\% el ordenador portátil, un $1,68 \%$ otro tipo de dispositivos como son los GPS, y tan solo un $2,16 \%$, señalaba que no hacía uso de ningún dispositivo tecnológico cuando viajaba.

Es evidente la generalización del uso de estos aparatos, ahora bien, ¿para qué son utilizados una vez en destino? En el caso de los visitantes en Ávila cuatro acciones destacan sobre el resto de opciones preguntadas, "para hacer fotos y vídeos» 85,59\%, "para consultar mapas o usar el GPS» $85,29 \%$, «para hablar con la familia/amigos» $80,48 \%$ y «para buscar información general sobre mi destino 75,08\%».

Por el contrario, el uso del móvil como modo de pago todavía no está excesivamente extendido y los visitantes mostraban cierta duda al respecto, fundamentalmente por cuestiones de seguridad, de hecho, solo un 5,11\% reconoció utilizarlo para tales fines. Llama también la atención que a pesar de que Ávila cuenta con apps relacionadas con sus recursos monumentales (municipal o autonómica), menos de un $10 \%$ de los visitantes las manejaban en sus dispositivos, quizás por el desconocimiento sobre su existencia, aspecto que habría que mejorar en un corto-medio plazo. 
Actas del Seminario Internacional Destinos Turísticos Inteligentes:

nuevos horizontes en la investigación y gestión del turismo

Universidad de Alicante, 26 y 27 de octubre de 2017

Figura 9: EXPERIENCIA. Uso de los dispositivos tecnológicos (\%)

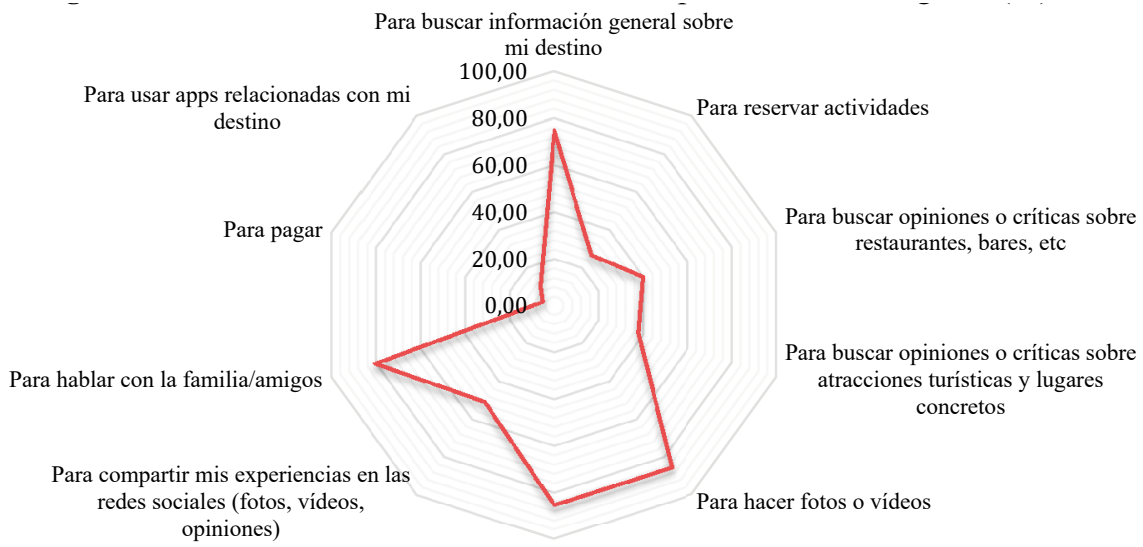

Para concultar mapas o usar el GPS

Ávila está trabajando para convertirse en Destino Turístico Inteligente de referencia, por tanto, es importante que los visitantes evalúen aquellos servicios, productos, infraestructuras que ofrece actualmente la ciudad, en aras de perfeccionarlos. El uso de cada uno de ellos es dispar, destaca la web del destino, como uno de los recursos más manejados (a la par que el mejor valorado); seguida de las audioguías (catedral y muralla) y las redes sociales del destino (Facebook y Twitter).

Cada uno de los aspectos que hemos considerado con antelación sumados a la propia experiencia del visitante permite cuantificar el grado de satisfacción de su estancia en la ciudad. Ávila parece estar trabajando en una buena dirección y es algo que aprecian tanto turistas como excursionistas, obteniendo una valoración media de 8,4 sobre 10 .

Las redes sociales se han convertido en un canal de comunicación indispensable en el s. XXI. Compartir información, opiniones, vídeos e imágenes es parte en sí misma de la propia experiencia del usuario en el lugar, ya que además de exponer sus vivencias se buscar la interactuación con otros interlocutores que pueden estar a km. de distancia. El 74\% de los visitantes de Ávila reconoció que compartiría algún tipo de información a través de las RR.SS. entre las más utilizadas se encuentran WhatsApp y Facebook. 
Actas del Seminario Internacional Destinos Turísticos Inteligentes: nuevos horizontes en la investigación y gestión del turismo

Universidad de Alicante, 26 y 27 de octubre de 2017

Tabla 7: Servicios turísticos utilizados por el visitante

\begin{tabular}{|l|c|c|c|c|c|c|c|}
\hline \multirow{2}{*}{\multicolumn{1}{|c|}{ SERVICIOS }} & \multirow{2}{*}{ NO } & \multirow{2}{*}{ Sí } & \multicolumn{5}{c|}{ Valoración } \\
\cline { 5 - 9 } & & & 1 & 2 & 3 & 4 & 5 \\
\hline Redes sociales del destino & 284 & 40 & 1 & 3 & 4 & 14 & 18 \\
\hline Web oficial del destino & 230 & 106 & 1 & 2 & 18 & 49 & 36 \\
\hline Códigos QR & 333 & 3 & & & 1 & & 2 \\
\hline Wifi público gratuito & 320 & 16 & 4 & 1 & 2 & 2 & 7 \\
\hline Wifi gratuito en empresas del destino & 301 & 15 & 5 & 1 & 6 & 3 & 19 \\
\hline Apps oficiales del destino & 329 & 7 & 4 & & 1 & 2 & \\
\hline Audioguías & 268 & 68 & 5 & 8 & 13 & 26 & 16 \\
\hline Reservas online en la web del destino & 335 & 1 & & & & 1 & \\
\hline Pago a través del móvil & 332 & 4 & & & 1 & 1 & 2 \\
\hline Tarjeta Turística multiusos (VisitÁvila) & 320 & 16 & & & 1 & 7 & 8 \\
\hline
\end{tabular}

Fuente: Encuesta a visitantes. Destino piloto. Ávila. 2016. Proyecto de investigación «Nuevos enfoques para la planificación y gestión del territorio turístico: conceptualización, análisis de experiencias y problemas. Definición de modelos operativos para destinos turísticos inteligentes (TTI)». Ref-CSO2014-59193-R

Tabla 8: Principales RR.SS. utilizadas por el visitante de Ávila (respuesta múltiple).

\begin{tabular}{|l|l|l|}
\hline & \multicolumn{1}{|c|}{ Respuestas } & \multicolumn{1}{c|}{$\%$} \\
\hline Facebook & 160 & 33,97 \\
\hline Twitter & 14 & 2,97 \\
\hline Instagram & 58 & 12,31 \\
\hline WhatsApp & 226 & 47,98 \\
\hline Tripadvisor & 10 & 2,12 \\
\hline Telegram & 2 & 0,42 \\
\hline Booking & 1 & 0,21 \\
\hline Total & 471 & 100,00 \\
\hline
\end{tabular}

Fuente: Encuesta a visitantes. Destino piloto. Ávila. 2016. Proyecto de investigación «Nuevos enfoques para la planificación y gestión del territorio turístico: conceptualización, análisis de experiencias y problemas. Definición de modelos operativos para destinos turísticos inteligentes (TTI)». Ref-CSO2014-59193-R 
Actas del Seminario Internacional Destinos Turísticos Inteligentes:

nuevos horizontes en la investigación y gestión del turismo

Universidad de Alicante, 26 y 27 de octubre de 2017

\subsection{Perfil del visitante}

Con este apartado concluye el cuestionario, incorporando preguntas que básicamente persiguen obtener una serie de rasgos básicos del visitante de la ciudad, procedencia, condición socioprofesional, edad, género... Entre los visitantes existe una cierta paridad entre hombre y mujeres, si bien, este último grupo era ligeramente más numeroso, o al menos más propenso a responder las cuestiones trasladadas en la encuesta, representaban el $51,49 \%$ frente al $48,51 \%$. En este bloque se recopiló la información vinculada a la edad, lo que permitió establecer, tomando de referencia las generaciones definidas por el Barómetro de Tripadvisor, cuáles eran los grupos más numerosos en Ávila, predominando aquellos que conforman la denominada la Generación X, entre los 35-64 años, ya que representaban el 61,31\% del total de encuestados.

A continuación, el grupo de los millenials, entre los 18-34 años, también tenía una representatividad bastante considerable en la ciudad, ya que suponían del orden del $36 \%$. Por último, el grupo menos numeroso es del de la generación de los baby boomers, aunque no por ello con menos presencia en la ciudad. ${ }^{9}$

Figura 10: Grupos generacionales predominantes en Ávila

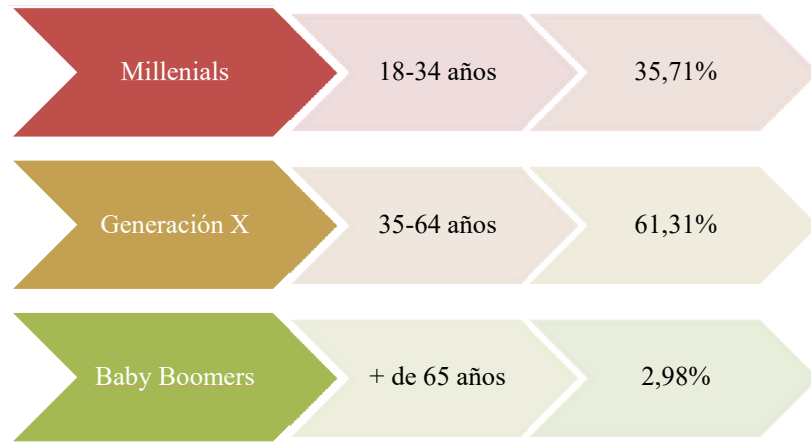

Fuente: Encuesta a visitantes. Destino piloto. Ávila. 2016. Proyecto de investigación «Nuevos enfoques para la planificación y gestión del territorio turístico: conceptualización, análisis de experiencias y problemas. Definición de modelos operativos para destinos turísticos inteligentes (TTI)». Ref-CSO2014-59193-R

9. No olvidemos que estamos analizando una encuesta vinculada a nuevas tecnologías y este grupo, no es de los usuarios mayoritarios de las mismas, de ahí, que al explicar el objetivo del cuestionario fueran más reacios a responder y quizás, esta generación quede algo infrarrepresentada en el presente informe. 
Actas del Seminario Internacional Destinos Turísticos Inteligentes:

nuevos horizontes en la investigación y gestión del turismo

Universidad de Alicante, 26 y 27 de octubre de 2017

Si prestamos atención al nivel de estudios de los visitantes, existe un claro predominio de aquellos que poseen estudios universitarios, $62 \%$, como también se reflejaba en las encuestas llevadas a cabo por el observatorio turístico.

El manejo de fuentes diversas como son los registros de los servicios de información turística (OIT's, CRV), la encuesta de ocupación hotelera (INE), así como los estudios relacionados con la demanda llevados a cabo por observatorio turístico de la ciudad, evidencian un claro predominio del visitante nacional frente al internacional.

Tabla 9: Procedencia de los visitantes

\begin{tabular}{|l|c|c|}
\hline \multicolumn{1}{|c|}{ Información } & Nacionales & Internacionales \\
\hline Centro de Recepción de visitantes (CRV).2016 & $76 \%$ & $24 \%$ \\
\hline $\begin{array}{l}\text { Encuesta de Ocupación Hotelera. Llegadas de viajeros a } \\
\text { establecimientos hoteleros. 2016 }\end{array}$ & $85 \%$ & $15 \%$ \\
\hline $\begin{array}{l}\text { Encuesta de coyuntura a la demanda (Observatorio } \\
\text { Turístico de Ávila). 2004 }\end{array}$ & $86 \%$ & $14 \%$ \\
\hline Encuesta a visitantes. DTI & $92 \%$ & $8 \%$ \\
\hline
\end{tabular}

Elaboración propia.

Centrándonos en los nacionales, hay dos factores que explican sus procedencias, en primer lugar, la localización de Ávila en el contexto de la región turística de Madrid, lo que determina un claro protagonismo del denominado visitante de proximidad y, en segundo lugar, el peso demográfico. De esta manera, observamos que, los madrileños son el grupo más numeroso, representando el $42 \%$ de los encuestados, seguidos de andaluces, $12,22 \%$, castellanoleoneses $11 \%$ y castellano-manchegos $7,07 \%$, menor presencia encontramos de catalanes y valencianos, 4,5 y $5 \%$, respectivamente. El resto de comunidades autónomas tiene una representatividad ínfima, alguna de ellas por debajo del $2 \%$, como es el caso de los aragoneses, gallegos, asturianos o los procedentes de ambos archipiélagos.

Respecto a los mercados internacionales, destacan los procedentes del continente europeo, representando el $48 \%$ de los encuestados (Portugal $12 \%$ Reino Unido $12 \%$, Francia $8 \%$, Italia $8 \%$ y Rusia $8 \%$ ) y los oriundos de 
Actas del Seminario Internacional Destinos Turísticos Inteligentes:

nuevos horizontes en la investigación y gestión del turismo

Universidad de Alicante, 26 y 27 de octubre de 2017

América Latina, 52\%, especialmente los provenientes de Argentina, $24 \%$ y México, $16 \%$.

Los resultados obtenidos de la encuesta reflejan la existencia de múltiples perfiles de visitantes en la ciudad de Ávila, bien sea por su procedencia, por el grupo generacional al que pertenecen, por su nivel educativo o por el dominio y uso que hacen de los dispositivos y nuevas tecnologías...Lo que es evidente es que si el público objetivo de los DTI son sus visitantes, es preciso que este tipo de herramientas de análisis se instauren en los entes de gestión turística, ya que son vías de obtención directa de información, y dada la evolución del Big Data, su tratamiento y explotación reportarían registros muy valiosos, no solo para perfilar estrategias de mercado, sino también para definir las actuaciones clave para lograr convertirse en un destino inteligente en sensu estricto.

\section{Conclusiones}

La recopilación de información explícita relacionada con la experiencia del "visitante actual-smart tourist» en destino, abre un espectro de oportunidades en el ámbito analítico. No existe mucha literatura al respecto, más allá del discurso, en ocasiones, excesivamente generalista, sustentado en los patrones del marketing turístico. Ciertamente la tendencia actual deriva hacia lo «inteligente», lo que implica la superación de cuestiones meramente tecnológicas y la necesidad de implementar en los territorios, una adecuada planificación que asuma todas las dimensiones propias de un lugar, así como crear infraestructuras de gestión acordes con las necesidades de los destinos y visitantes del s. XXI.

En esa línea, viene trabajando la ciudad de Ávila desde los últimos años del pasado siglo XX. La confluencia de una serie de factores favorables, políticos, urbanísticos, patrimoniales, así como económicos, y, especialmente, un protagonismo decidido de la administración municipal, posibilitaron un salto cualitativo en su proceso de conformación como destino turístico, que hoy en día sigue vigente y se orienta hacia su posicionamiento como uno de los destinos patrimoniales inteligentes de referencia nacional e internacional. Para ello, se está interviniendo en términos urbanísticos y patrimoniales, avanzando sobre la recuperación de edificios monumentales, peatonalización, mejora de la movilidad..., así como en clave turística, diseñando nuevos productos, adecuando elementos y zonas clave del patrimonio abulense 
Actas del Seminario Internacional Destinos Turísticos Inteligentes:

nuevos horizontes en la investigación y gestión del turismo

Universidad de Alicante, 26 y 27 de octubre de 2017

para su correcta articulación, creando sistemas de gestión integrada de visitas, etc,

La preocupación por ahondar en las características de sus visitantes es permanente, y los estudios desarrollados por el observatorio turístico de la ciudad, se complementan con otras investigaciones como la expuesta en el presente trabajo, que permite cruzar información más tradicional de la demanda como son sus motivaciones, imágenes, comportamientos y características sociodemográficas, con aspectos derivados de la reflexión sobre el perfil del nuevo visitante 3.0. Ávila, sigue siendo un destino cuyo reconocimiento como Patrimonio Mundial es factor principal de atracción para un visitante predominantemente nacional, excursionista, de la llamada Generación $X$ (35-64 años), que ha incorporado en sus pautas de viaje el uso de los dispositivos móviles, con el fin de obtener información del destino de una manera rápida. Los smartphone han ido ganando terreno a las cámaras fotográficas y además de captar imágenes, el usuario las comparte a través de sus redes sociales, siendo esta acción, parte también de la propia experiencia.

Este tipo de proyectos suponen un interesante campo de investigación que permite obtener nuevos datos con los que profundizar en la evolución de los territorios en la lógica de los DTI.

\section{Bibliografía}

AENOR (2016): Norma PNE 178501 «Sistema de Gestión de Destinos Turísticos Inteligentes SGDTI. Asociación Española de Normalización y Certificación, AENOR. Ayuntamiento de Ávila. (2002). Observatorio Turístico de Ávila. Boletín n.o'1. Pp. 10 Ayuntamiento de Ávila. (2005). Observatorio Turístico de Ávila. Boletín n.⒎ Pp. 15 Ayuntamiento de Ávila. (2016). Observatorio Turístico de Ávila. Boletín n.42. Pp. 13 Blanco, J. (2015). Libro Blanco de los Destinos Turísticos Inteligentes. Estrategias y soluciones para fomentar la innovación en el turismo digital. Ed. Altrán. Madrid. Pp. 164.

Caro, J. L., Luque, A. M., \& Zayas Fernández, B. (2014). Aplicaciones tecnológicas para la promoción de los recursos turísticos culturales. En XVI Congreso Nacional de Tecnologías de la Información Geográfica 25, 26 y 27 de Junio de 2014. Alicante.

Calle Vaquero, M. de la; García Hernández, M. (2016). «Políticas turísticas en ciudades históricas españolas. Génesis, evolución y situación actual» ${ }_{2}$ en Pasos. Revista de Turismo y Patrimonio Cultural. Vol. 14 (3). Pp. 691-704. ISSN 16957121. 
Actas del Seminario Internacional Destinos Turísticos Inteligentes:

nuevos horizontes en la investigación y gestión del turismo

Universidad de Alicante, 26 y 27 de octubre de 2017

Castells, M. (2004). La era de la información: economía, sociedad y cultura (Vol. 3). siglo XXI.

Charan, D; Chouhan, A; Pereira, A. (2016). "Smart Tourism System». International Journal os Engineering and Computer Science. Vol. 5. Pp. 29-31.

Díaz, L.F. (1996). «Los viajeros costumbristas romántico». Actas del VI Congreso. El costumbrismo romántico. Pp. 109-116

Eger, J. (1997). Cyberspace and cyberplace: Building the smart communities of tomorrow. San Diego Union-Tribune. Insight.

Exceltur. (2017). UrbanTur. Monitor de competitividad Turística de los destinos Urbanos españoles. Madrid. Pp. 186

Fundación Santa María la Real. Smart Heritage City. http://shcity.eu/

González, L. (2017). Cinco características que diferencian al turista 3.0. [Recuperado de http://www.cognodata.com/notas_de_prensa/cinco-caracteristicas-que-diferencian-al-turista-3-0/]

HOSTELTUR (2009). Turismo 2.0 una sección paradigmática del in-formar. [Recuperado de http://www.een.edu/descargas/1/es/turismo-y-web-2.pdf. Consultado Instituto Nacional de Estadística. Encuesta de Ocupación Hotelera. 2016.

INVAT-TUR (2015). Manual operativo para la configuración de destinos turísticos inteligentes. Ed. INVAT-TUR. P.141. http://invattur.gva.es/estudio/manual-operativo-para-la-configuracion-de-destinos-turisticos-inteligentes/ [Consultado 25-04-2017]

Lazzarotti, O. (2000): «Patrimoine et Tourisme: un Couple de la Mondialisation». Mappemonde, 57, 12-16.

López Ávila, A. y García Sánchez, S. (2013): «Destinos turísticos inteligentes». Harvard Deusto business review, 224, 56-67.

Luque Gil, A. M., Zayas Fernández, B., Herrero, C., \& Luis, J. (2015). "Los Destinos Turísticos Inteligentes en el marco de la Inteligencia Territorial: conflictos y oportunidades». Investigaciones turísticas n.ㅇ 10. Julio-diciembre. Pp. 1-25

Mascaró, T. (2013). Smart Tourist y Smart Destination. [Recuperado de https:// www.hosteltur.com/117370_smart-tourist-smart-destinations.html [Consultado 10/05/2017]

Mínguez García, M.C. y Ruiz Jiménez, P. (2014). «Los Destinos Turísticos Inteligentes en España: ¿un proyecto institucional o el futuro del sector?» En el XIV Coloquio de Geografía del Turismo, Ocio y Recreación: "Espacios turísticos e inteligencia territorial. Respuestas ante la crisis», organizado por la Asociación de Geógrafos Españoles, Grupo de Geografía del Turismo, Ocio y Recreación, Universidad de Málaga y Universidad de Sevilla. Celebrado en Málaga-Sevilla del 23 al 25 de octubre.

Ministerio de Industria, Energía y Turismo. (2012). Plan Nacional e Integral de Turismo 2012-2015. Madrid. P. 124 
Actas del Seminario Internacional Destinos Turísticos Inteligentes:

nuevos horizontes en la investigación y gestión del turismo

Universidad de Alicante, 26 y 27 de octubre de 2017

Ministerio de Industria, Energía y Turismo. (2015). Plan Nacional de Ciudades Inteligentes. Madrid. P. 35.

Nadal, P. (2011) ¿Por qué ser turista es malo y ser viajero, mola? [Recuperado de http://elpais.com/elpais/2010/11/14/paco_nadal/1289689200_128968.html. [Consultado 17/05/2017]

OCDE (2009). El Impacto de la Cultura en el Turismo. México, SECTUR

Prensky, M. (2001). «On the Horizon». MCB University Press, Vol. 9 No. 5, October. 2001

Redondo, M. (2016). Turista 3.0, la experiencia de viaje es lo más importante.

[Recuperado de https://cincodias.elpais.com/cincodias/2016/01/07/sentidos/1452189782_740203.html. Consultado 20-05-2017

Reverté, F. G., \& Clavé, S. A. (2008). La naturaleza del turista. De la turismofobia a la construcción social del espacio turístico. In A propósito del turismo: la construcción social del espacio turístico (pp. 11-34). Editorial UOC.

Sader, M. (2016). Turistas y viajeros, ¿especies irreconciliables?. [Recuperado de TRAVELER. http://www.traveler.es/viajes/mundo-traveler/articulos/turistas-y-viajeros-especies-irreconciliables/8666) [Consultado 29/05/2017]

SEGITTUR (2015). Libro Blanco de Destinos Turísticos Inteligentes: construyendo futuro. Ed. Ministerio de Industria, Energía y Turismo. Madrid. P. 207. [Recuperado de http://www.segittur.es/es/DTI/dti-detalle/Libro-Blanco-Destinos-Tursticos-Inteligentes-/\#.V2pgbPmLTcs [Consultado 17-05-2017]

Tripadvisor (2016). TripBarometer 2016. Traveler Trends \& Motivations. Global Findings. Pp. 65. [https://www.tripadvisor.es/TripAdvisorInsights/TripBarometer-ES\#tab=0 Consultado 20-05-2017]

Troitiño Torralba, L. (2010). Madrid y los destinos patrimoniales de su región turística. E-prints. UCM.

Troitiño Vinuesa,M.Á; Troitiño Torralba, L. (2016). «Patrimonio y turismo: reflexión teórico conceptual y una propuesta metodológica integradora aplicada al municipio de Carmona (Sevilla, España)». Scripta Nova, Vol XX, núm. 543 (1 de septiembre de 2016). ISSN: 1138-9788.

Troitiño Vinuesa, M.A. y Troitiño Torralba, L. (2009). «Turismo y Patrimonio en Castilla y León: Las Ciudades Patrimonio de la Humanidad (Ávila, Salamanca y Segovia) como destinos turísticos de referencias». Polígonos. Revista de Geografía, n.o 19. Número Monográfico: Nuevas Contribuciones sobre Castilla y León. Pp. 145-178. ISSN: 1132-1202 
Actas del Seminario Internacional Destinos Turísticos Inteligentes:

nuevos horizontes en la investigación y gestión del turismo

Universidad de Alicante, 26 y 27 de octubre de 2017

Troitiño Vinuesa, M. A. (2002). «Ciudades Españolas Patrimonio de la Humanidad:

Desafíos de Interpretación y de Gestión». PH, Boletín del Instituto Andaluz del Patrimonio Histórico, 40/41. Pp. 153-165. ISSN: 1136-1867

Troitiño Vinuesa, M. A; Calle Vaquero, M. de la y García Hernández, M. (2002). Afluencia y Perfil de los Visitantes de la Ciudad de Ávila. Ayuntamiento de Ávila / Junta de Castilla y León / Ministerio de Economía. Ávila. ISBN: 84-606-3222-9 Turismo y Viajes (2017). ELECONOMISTA. http://www.eleconomista.es/turismo-viajes-modulo/noticias/7931913/11/16/Eres-un-smart-traveller.html [Consultado 29/05/2017]

Vargas-Sánchez, A. (2016). Exploring the concept of smart tourist destination. Enlightening tourism. A pathmaking journal, 6(2), 178-196.

Vegara, A; De las Rivas, J.L. (2004). Territorios inteligentes. Nuevos horizontes del urbanismo. Ed. Fundación Metrópoli. Madrid. P. 328. https://issuu.com/fundacionmetropoli/docs/territorios_inteligentes_fundacion_metropoli [Consultado 4-05-2017]

Vegara, A (2009). Territorios inteligentes. Revista Ambienta: La revista del Ministerio de Medio Ambiente, n.o 89, pp. 34-58

Vera Rebollo, J.F. -coord.-; López Palomeque, F.; Marchena, M.; Antón, S. (2011). Análisis territorial del turismo y planificación de destinos turísticos. Valencia. Tirant lo Blanch. 